\title{
PHYSICAL ACTIVITY AMONG UNIVERSITY STUDENTS
}

\author{
Evelina Miloshova \\ National Sports Academy "Vassil Levski", Sofia, Bulgaria
}

\begin{abstract}
Insufficient or lack of physical activity is one of the main risk factors that contribute to the development of some health problems and their progress. More common with physically inactive people diseases do not end up completely healing, but with chronification. The leading causes of mortality among the population worldwide are cardiovascular diseases, diabetes, obesity, and cancer. There is a tendency for "rejuvenation" of these diseases, their frequency relative increased in the population of young people. The aim of the present study is to establish the level of physical activity among young people, with particular focus on university students.

Material and methods. A survey was conducted (November 2018 - January 2019) among students from some universities in Sofia, Bulgaria (Technical University, UNWE, NSA). The short version of the International Physical Activity Questionnaire (IPAQ-SF) has been used. The total number of respondents was 435 (238 men and 197 women) aged 19-29 (Mean $\pm S D 23.3 \pm 2.3$ years).

Results. Approximately $12 \%$ of respondents have no physical activity except for walking. Both men and women practiced various physical activities most often twice a week. Women spend approximately an hour for exercises and men - 1.5 hours a day. Men prefer intensive workloads, while women - moderate. Daily respondents spend sitting for about 7 hours.
\end{abstract}

Key words: physical activity, IPAQ-SF, university students

\section{INTRODUCTION}

Health promotion is a priority for both individuals and society as a whole. Personal health care includes rational nutrition (Gaesser et al., 2015; Rosenheck, 2008; Sachdeva, et al., 2013) physical activity (PA) (Paffenbarger \& Lee, 1998; Bray \& Born, 2004; Reed \& Phillips, 2005; Dimitrova, 2014; Wasilewska \& Bergier, 2015), avoiding stress, smoking, and alcohol use (Kotarov, 2008; Diamond, 2015; Paganini-Hill, et al., 2007; Schuch \& Stubbs, 2019), and from the public - adequate health care, prevention of non-communicable, socially significant diseases, etc. (WHO, Dimitrova D., 2014).

Lack of physical activity is one of the major risk factors contributing to the occurrence of some health abnormalities and their development. In physically inactive people, it is more often the case that these diseases do not end in complete healing but are chronic. The leading causes of worldwide mortality are cardiovascular disease, diabetes, obesity, and cancer. There is a tendency for "rejuvenation of these diseases", i.e. their relative occurrence in younger people is increasing.

Low physical activity is one of the major risk factors for the occurrence of chronic diseases. The National Behavioral Risk Factor Survey Among Population aged 25-64 (2009) reveals some disturbing facts, for example: “... over $80 \%$ of the active age population have underweight leisure activity; of them do not practice physical exercise at all - 75\% „. The Annual Health Report (2013) states: „... only $2 \%$ of those surveyed above the age of 15 years regularly sport and 78\% do not practice sports at all". Physical activity indicators of the population in Bulgaria are the lowest in Europe, and insufficient physical activity, together with other risk factors, leads to higher morbidity and mortality from non-communicable diseases.

It is generally accepted that young people have the highest physical activity compared to other age groups in the population. However, several studies show that, after leaving school, a large proportion of young people are practically breaking sports and caring to maintain good shape (Youth Strategy, 2015; Mitev \& Kovacheva, 2014). Data from the Eurobarometer (2017) on the physical activity of Bulgarians show that $34 \%$ of young people in high school and college-age (15-24 years) do not exercise any physical activity or sport.

The present study aims to establish the level of physical activity among young people, with a particular focus on university students. 


\section{METHODOLOGY}

This study had a cross-sectional retrospective design and was approved by the Ethics Committee of the National Sports Academy.

A survey was conducted (November 2018 - January 2019) among students from some universities in Sofia, Bulgaria (Technical University, UNWE, NSA). The short version of the International
Physical Activity Questionnaire (IPAQ-SF) has been used, which explores physical activity for the last seven days. The total number of respondents was 435 (238 men and 197 women) aged 19-29 (Mean \pm SD $23.3 \pm 2.3$ years). The survey was conducted online using a Google Form. The results were processed using the IBM SPSS v.19.0 statistical program.

\section{RESULTS AND DISCUSSION}

Table 1. Physical activity of respondents according to intensity

\begin{tabular}{|c|c|c|c|c|c|c|c|}
\hline \multirow{3}{*}{\begin{tabular}{|c|} 
\\
Vigorous PA \\
- Days/week \\
- Minutes/day \\
- MET min/week \\
\end{tabular}} & \multicolumn{2}{|c|}{$\begin{array}{c}\text { Male } \\
(n=238)\end{array}$} & \multicolumn{2}{|c|}{$\begin{array}{r}\text { Female } \\
(n=197)\end{array}$} & \multirow{3}{*}{\begin{tabular}{l}
\multicolumn{1}{c}{$\begin{array}{c}\text { Mean } \\
\text { difference }\end{array}$} \\
$1,32^{* *}$ \\
$38,45^{* *}$ \\
$1556,0^{* *}$
\end{tabular}} & \multicolumn{2}{|c|}{$\begin{array}{c}\text { Total } \\
(n=435)\end{array}$} \\
\hline & \multicolumn{2}{|c|}{ Mean } & \multicolumn{2}{|c|}{ Mean SD } & & \multicolumn{2}{|c|}{ Mean SD } \\
\hline & $\begin{array}{l}3,32 \\
96,09 \\
3157,3\end{array}$ & \begin{tabular}{|l}
2,0 \\
72,6 \\
3084.1
\end{tabular} & $\begin{array}{l}2,0 \\
57,64 \\
1591.2\end{array}$ & $\begin{array}{l}2,04 \\
63,7 \\
2033.1\end{array}$ & & $\begin{array}{l}2,72 \\
78,68 \\
2448,1\end{array}$ & $\begin{array}{l}2,2 \\
71,3 \\
2769,5\end{array}$ \\
\hline $\begin{array}{l}\text { Moderate PA } \\
\text { - Days/week } \\
\text { - Minutes/day } \\
\text { - MET min/week }\end{array}$ & $\begin{array}{l}2,6 \\
81,62 \\
1265.7\end{array}$ & \begin{tabular}{|l}
2,2 \\
78,6 \\
1921.5
\end{tabular} & $\begin{array}{l}1,96 \\
62,69 \\
808.0\end{array}$ & \begin{tabular}{|l}
1,9 \\
60,2 \\
1184.3
\end{tabular} & $\begin{array}{l}0,64^{*} \\
18,92^{*} \\
457,7^{*}\end{array}$ & $\begin{array}{l}2,31 \\
73,05 \\
1058,4\end{array}$ & $\begin{array}{l}2,1 \\
71,4 \\
1643,7\end{array}$ \\
\hline $\begin{array}{l}\text { Walking } \\
\text { - Days/week } \\
\text { - Minutes/day } \\
\text { - MET min/week }\end{array}$ & $\begin{array}{l}5,97 \\
114,37 \\
2334,5\end{array}$ & \begin{tabular}{|l}
1,7 \\
86,6 \\
1981,5
\end{tabular} & $\begin{array}{l}6,01 \\
120,28 \\
2425,8\end{array}$ & \begin{tabular}{|l}
1,5 \\
94,5 \\
2066,2
\end{tabular} & $\begin{array}{l}-0,04 \\
-5,9 \\
-91,21\end{array}$ & $\begin{array}{l}5,98 \\
117,05 \\
2375,8\end{array}$ & $\begin{array}{l}1,6 \\
90,2 \\
2018,5\end{array}$ \\
\hline $\begin{array}{l}\text { Sitting } \\
\quad \text { - Hours/day }\end{array}$ & 6,94 & 4,4 & 7,30 & 3,1 & $-0,36$ & 7,11 & 3,8 \\
\hline
\end{tabular}

${ }^{\star} p<0,05 ;{ }^{* *} p<0,01$

Students' physical activity is represented by their intensity - vigorous physical activity (VPA), moderate (MPA) and walking. The results obtained indicate the frequency of PA exercises within the day and weekly, comparing data by gender (Table 1).

The surveyed students are physically active most days of the week. The percentage of those performing only VPA (14.9\%) or MPA (14.5\%) is approximately the same.

Almost two-thirds of students practice both vigorous and moderate physical activity. Only $12 \%$ do not exercise at all, as physically inactive women are three times more than men. Vigorous PA is preferred by men while ladies' practice more moderate-intensity activities. Only 12\% do not perform any physical activity.

Frequency and duration of $P A$ depending on intensity Intensive PA is practiced 2-3 days a week, with an average duration of 1-1.5 hours (78.7 $\mathrm{min} /$ day).
One-fifth of students complete a VPA within 1 hour and equally - between 1 and 2 hours. About $31 \%$ of respondents' activities continued over 120 minutes. Moderate PA is performed 1-2 days per week, with sessions lasting just over 1 hour ( $73 \mathrm{~min} /$ day). The duration of MFA during the day for one-third of students is up to 1 hour, for $13 \%$ - is more than 1 hour, and for $27.8 \%$ - more than 2 hours per day. Walking is a physical activity that is present in the daily routine of all students, with $61 \%$ of them walking through all seven days of the week, between 1 and 2 hours a day. Walking longer than 5 hours is typical for $6.2 \%$ of the respondents. Only $1.4 \%$ of students report not walking during the day.

\section{Physical activity by gender}

The preferred PA for men is with greater intensity and longer duration. Students exercise it on average 3 days a week for about an hour and a half (96 $\mathrm{min}$ /day) and women exercise 2 days a week for 1 hour (58 $\mathrm{min} /$ day), with statistically significant dif- 
ferences ( $\mathrm{p}<0.01$ ). A similar distribution is observed concerning moderate-intensity PA. Both sexes practice this activity about 2 days a week (2.6 for men and 1.96 for women, $\mathrm{p}<0.05$ ), and duration is $82 \mathrm{~min} /$ day for men and $63 \mathrm{~min} /$ day for women.

The duration of vigorous activities in men is up to 60 minutes for $20.2 \%$ of them, for a quarter - 60 -
120 minutes, and $39.5 \%$ are engaged in more than two hours daily.

In women, the highest percentage (22.3\%) spend 1 hour a day engaging in vigorous exercise, and this percentage decreases as the duration of the exercise increases (Figure 1).

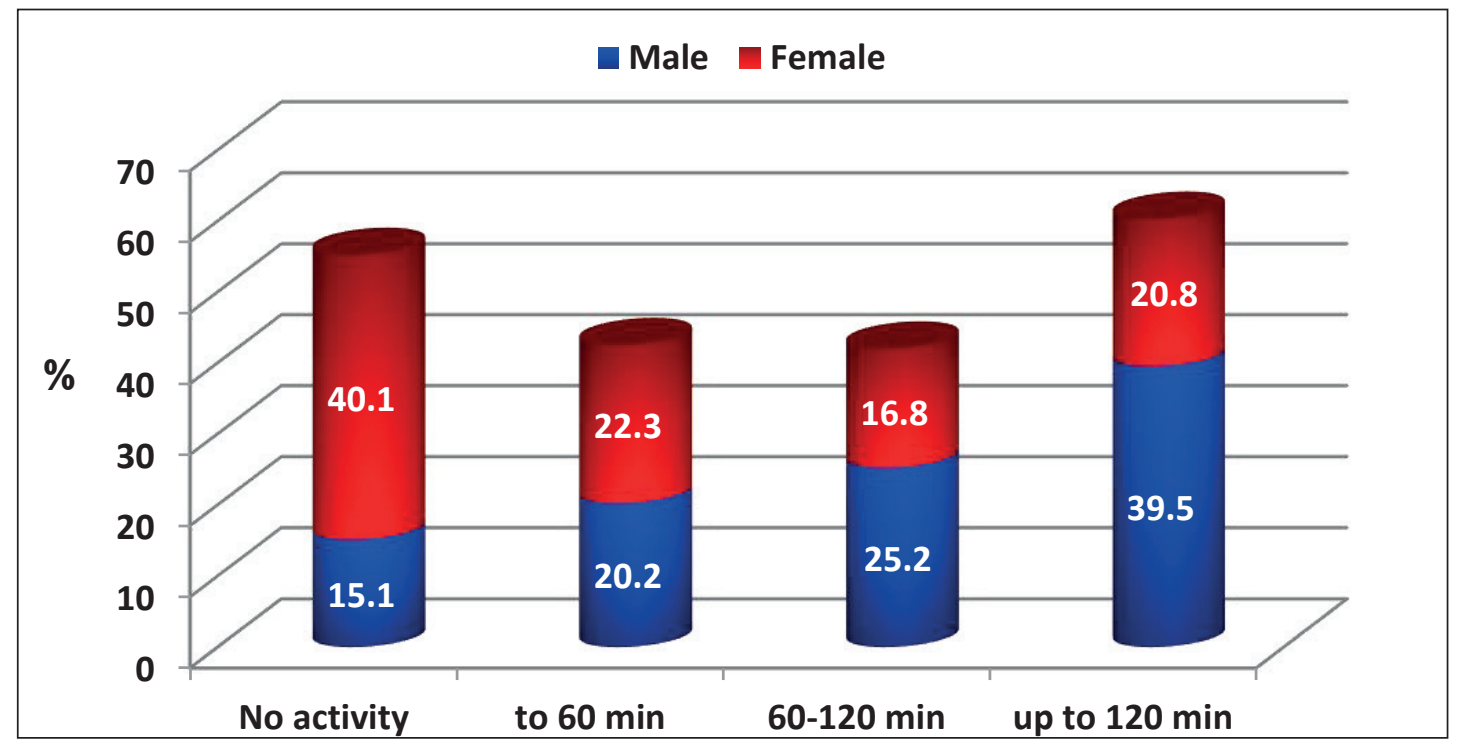

Figure 1. Duration of vigorous physical activity

Women prefer moderate-intensity exercises. For just as many of them devote to this PA over 2 hours about one-third, the activities last up to 1 hour, but of their time (Figure 2).

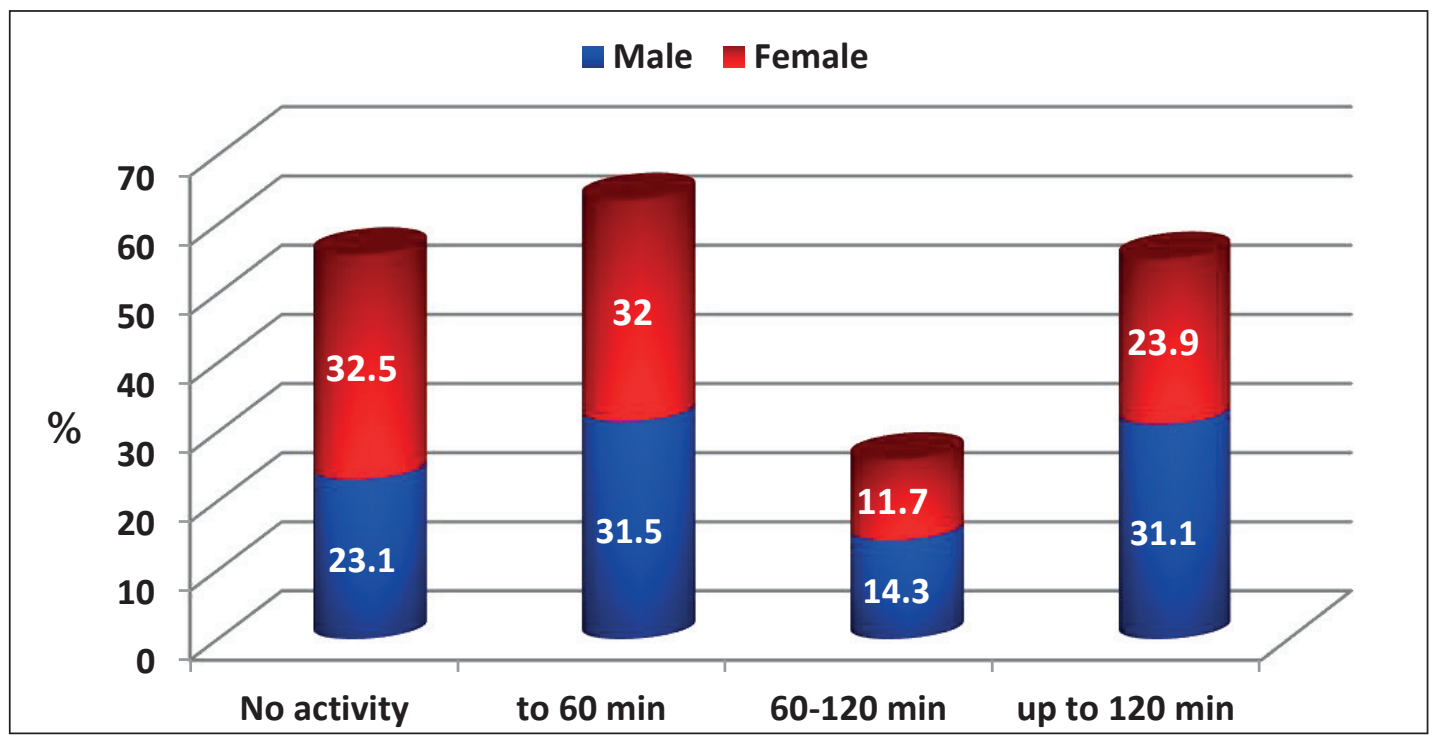

Figure 2. Duration of moderate physical activity

For more than half of the students (58.6\%), the sically inactive males are $5 \%$, while females are 4 PAs they practice are both vigorous and moderate, times more (Figure 3).

but $12 \%$ do not have any PAs. Male students prefer vigorous workloads, while female - moderate. Phy- 


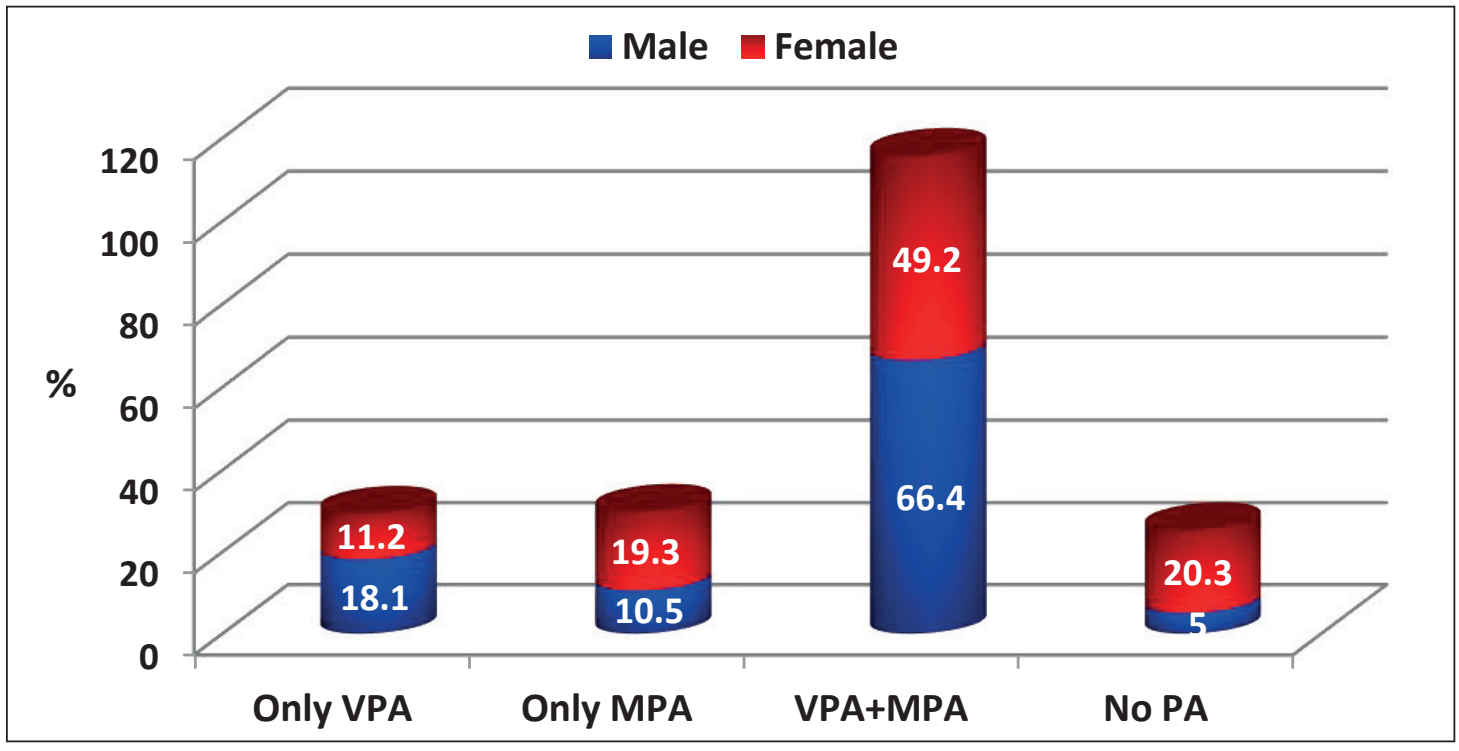

Figure 3. Preferred physical activity by gender

Walking, as an active mode of movement, is typical for both sexes. Male students walk at least one hour each day of the week, and the female students - five days a week, but two to three hours.

\section{Energy consumption}

The determination of energy consumption for different types of PA was made by calculating the Metabolic Equivalents of Task (METs). The results show that the amount of energy expended in vigorous and moderate-intensity PA is 1.5-2: 1 in favor of men (see Table 1), with statistically significant differences. The walking energy consumption is practically the same (2334.5 MET for male and 2425.8 MET for female students) (Figure 4).
The total energy expenditure that includes vigorous and moderate-intensity PA and walking within a week is 6757.6 MET for men and 4825 MET for women $(\mathrm{p}<0.05)$.

\section{Sedentary}

The time spent interviewed sitting (reading, working with a computer, watching TV) takes an average of 7 hours a day, with minor differences between the sexes. Two-thirds of the ladies spend 7-10 hours in a sitting position, while in men the highest percentage (45.8\%) is 3 to 7 hours. In both genders, the percentage of those who sit most of the day in a sitting position (over 10 hours) is approximately equal ( $7.4 \%$ for men and $5.1 \%$ for women).

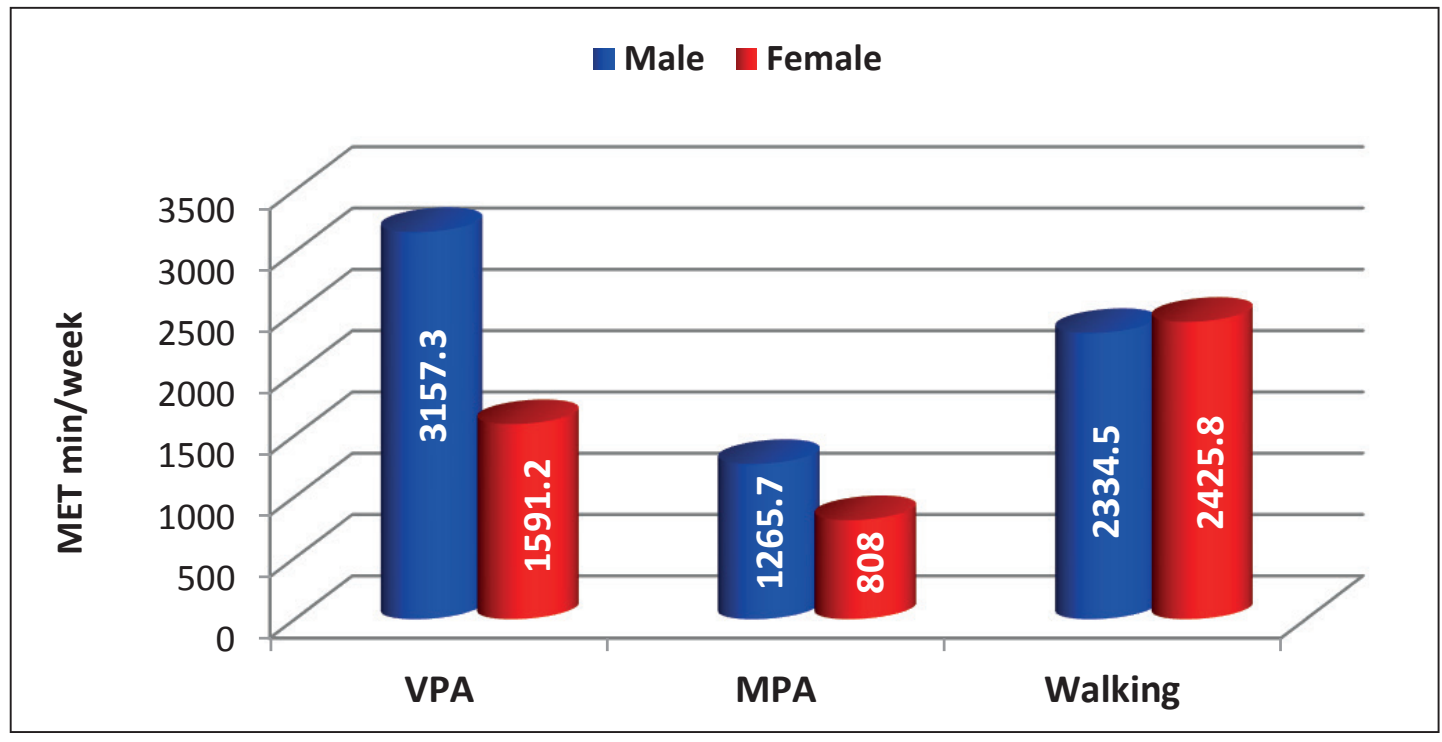

Figure 4. Metabolic Equivalents of Task according to different activities 
According to the referred studies, there are similarities in the practice of PA by students in different countries around the world (Bednarek, et al., 2016; Fagaras, et al., 2015; Chiang, et al., 2013). All studies examine the PA using IPAQ-SF, but there is a large difference in the number of respondents.
The data from all the articles shows that men have greater PA than women, with vigorous exercises being preferred. Students from the USA and Bulgaria have the highest physical activity, and those from Turkey have the lowest physical activity (Figure 5).

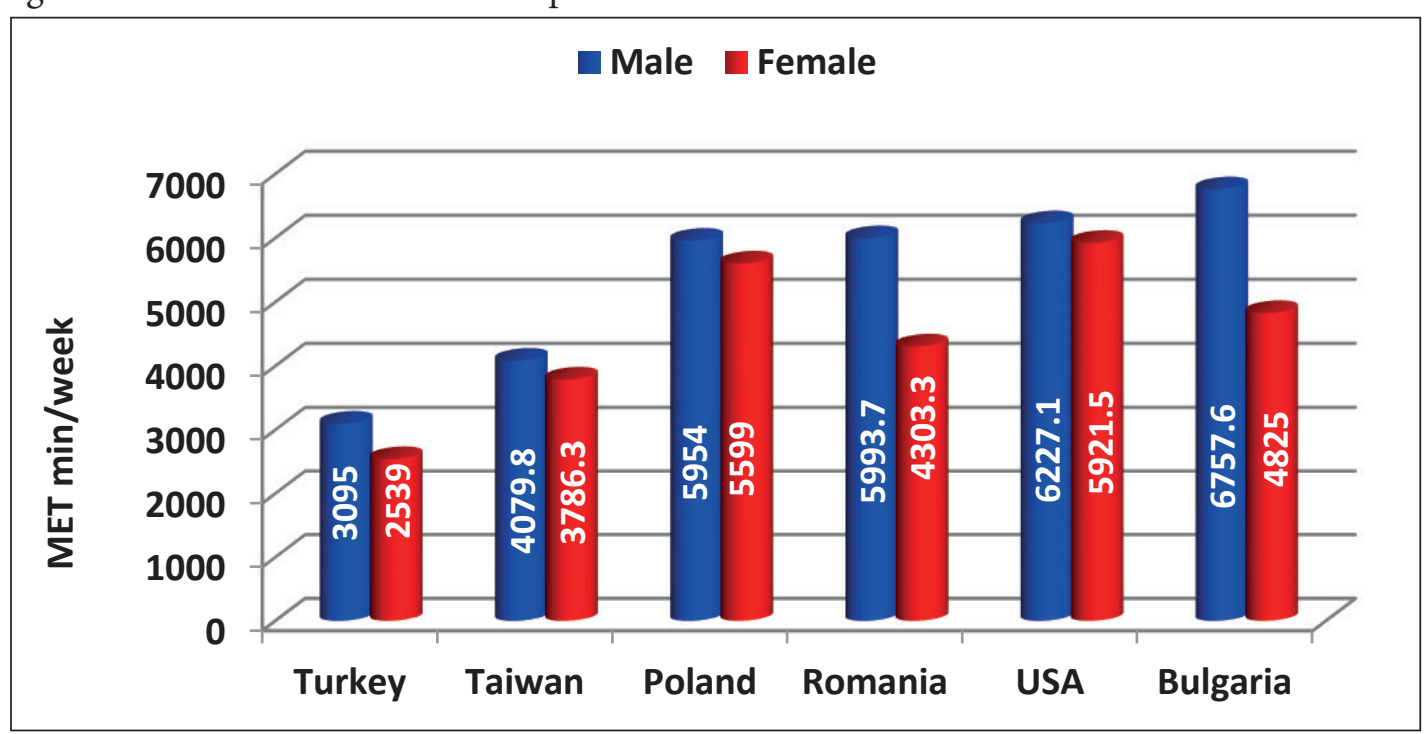

Figure 5. Physical activity of university students in different countries expressed in MET-minutes/week

\section{CONCLUSION}

According to WHO recommendations on physical activity leading to improved health, intense PAs are required for at least 75 minutes a week or 300 minutes at moderate intensity. The energy cost of these activities, incl. walking is desirable to be not less than $3000 \mathrm{MET} \mathrm{min} /$ week.

There are also health benefits when performing moderate-intensity activities 5 times a week for at least 30 minutes a day, with a total energy expenditure (MPA + walking) of at least 600 MET.

In the context of these criteria, the respondents have a good level of PA, as their energy consumption exceeds that recommended. Nevertheless, a more detailed study is needed, for a longer time interval, because of the data in the Youth Report 2015 and the recommendations made in the National Youth Strategy 2012-2020 based on these data. These documents focus on the physical activity of school-age children and less on young people between the ages of 19 and 29.

\section{REFERENCES}

Annual health report and implementation of the National Health Strategy for 2013. http://ncpha.government. bg/files/doklad_2013\%281\%29.pdf

Bednarek J., Pomykala S., Bigosinska M. and Szygula Z. (2016) Physical activity of Polish and Turkish university students as assessed by IPAQ. Central European Journal of Sport Sciences and Medicine, 16 (4): 13-22; doi: 10.18276/cej.2016.4-02

Bray, S.R., \& Born, H.A. (2004). Transition to university and vigorous physical activity: Implications for health and psychological well-being. I Am College Health, 52(4): 181-188

Chiang, LM., Zhang, P., Casebolt, K. and Chiang, J. (2013). A Comparison of College Students' Physical Activity Levels between Taiwan and the United States. Asian Journal of Exercise \& Sports Science, 10 (2): 49-59

Diamond, A. (2015). The Cognitive Benefits of Exercise in Youth. Cur Sports Med Rep, 14 (4): 320-326. doi: 10.4103/0970-0218.120146

Dimitrova D. Physical activity and health. Avangard Prima, Sofia 2014

Fagaras, SP., Radu, LE. and Vanvu, G. (2015). The Level of Physical Activity of University Students. Procedia - Social and Behavioral Sciences, 197: 1454 - 1457; doi: 10.1016/j.sbspro.2015.07.094

Gaesser, G., Tucker, WJ., Jarrett, CL. and Angadi, S. (2015). Fitness versus Fatness: Which Influences Health and Mortality Risk the Most? Cur Sports Med Rep, 14 (4): 327-332 
http://www.euro.who.int/en/health-topics/disease-prevention/physical-activity

Kotarov, G. (2008). Mental health promotion and prevention of mental illness. http://ncphp.government.bg/ files/projects/Mental_health_promotion.pdf

Mitev, PE. \& Kovacheva, S. (2014). Young people in European Bulgaria. Sociological portrait. Ed. The Friedrich Ebert Foundation, Bureau of Bulgaria. Sofia.

National behavioral risk factor survey among population aged 25-64 (2009). Bulg J Pub Health, Supplement, Vol. I, № 3(1)

National Youth Strategy (2012 - 2020), http://mpes.government.bg/Documents/Documents/Strategii/strategy_ youth_2012-2020.pdf

Paffenbarger, RS. Jr \& Lee, IM. (1998) A natural history of athleticism, health and longevity. J Sports Sci, 16: 3145

Paganini-Hill, A., Kawas, CH. and Corrada, MM. (2007). Non-alcoholic beverage and caffeine consumption and mortality: the Leisure World Cohort Study. Prev Med. 44 (4): 305-310.

Reed, JA. \& Phillips, A. (2005). Relationships Between Physical Activity and the Proximity of Exercise Facilities and Home Exercise Equipment Used by Undergraduate University Students. J Am College Health, 53 (6): 285-290 Rosenheck, R. (2008). Fast food consumption and in- creased caloric intake: a systematic review of a trajectory towards weight gain and obesity risk. Obesity reviews 9: 535-547; doi: 10.1111/j.1467-789X.2008.00477.x

Sachdeva, S., Sachdev, TL., and Sachdiva, R. (2013). Increasing Fruit and Vegetable Consumption: Challenges and Opportunities. Indian J Community Med. 38 (4): 192-197.

Schuch FB \& Stubbs B. (2019). The Role of Exercise in Preventing and Treating Depression. Cur Sports Med Rep, 18 (8): 299-304

Special Eurobarometer (2017). Sport and physical activity. Bulgaria. https://ec.europa.eu/commfrontoffice/publicopinion/index.cfm/survey/getsurveydetail/instruments/special/surveyky/2164

Wasilewska M. \& Bergier J. (2015). Physical activity level of the youth in selected countries of the world. Health Problems of Civilization, 3 (9): 39-46.

Youth Report (2015) Republic Of Bulgaria, Ministerial Council, www.strategy.bg/FileHandler.ash $x$ ?fileId $=9460$

Corresponding address: Evelina Miloshova MD, $\mathrm{PhD}$ National Sports Academy "V. Levski", Studentski grad 1700, Sofia, Bulgaria E-mail: emiloshova@yahoo.com 